\title{
Response of the Nevzorov hot wire probe in clouds dominated by droplet conditions in the drizzle size range
}

\author{
A. Schwarzenboeck ${ }^{1,2}$, G. Mioche ${ }^{1,2}$, A. Armetta ${ }^{1,2}$, A. Herber ${ }^{3}$, and J.-F. Gayet ${ }^{1,2}$ \\ ${ }^{1}$ Clermont Université, Université Blaise Pascal, LAMP, 63177 Aubière, France \\ ${ }^{2}$ CNRS, UMR 6016, LAMP, 63173 Aubière, France \\ ${ }^{3}$ Alfred Wegener Institute for Polar and Marine Research (AWI), Columbusstrasse, 27568 Bremerhaven, Germany
}

Received: 27 April 2009 - Published in Atmos. Meas. Tech. Discuss.: 15 May 2009

Revised: 20 October 2009 - Accepted: 30 October 2009 - Published: 4 December 2009

\begin{abstract}
During the airborne research mission ASTAR 2004 (Arctic Study of Tropospheric Aerosols, Clouds and Radiation) performed over the island of Svalbard in the Arctic a constant-temperature hot-wire Nevzorov Probe designed for aircraft measurements, has been used onboard the aircraft POLAR 2. The Nevzorov probe measured liquid water (LWC) and total condensed water content (TWC) in supercooled liquid and partly mixed phase clouds, respectively. As for other hotwire probes the calculation of LWC and/or TWC (and thus the ice water content IWC) has to take into account the collection efficiencies of the two separate sensors for LWC and TWC which both react differently with respect to cloud phase and what is even more difficult to quantify with respect to the size of ice and liquid cloud particles. The study demonstrates that during pure liquid cloud sequences the ASTAR data set of the Nevzorov probe allowed to improve the quantification of the collection efficiency, particularly of the LWC probe part with respect to water. The improved quantification of liquid water content should lead to improved retrievals of IWC content. Simultaneous retrievals of LWC and IWC are correlated with the asymmetry factor derived from the Polar Nephelometer instrument.
\end{abstract}

\section{Introduction}

Condensed water content (CWC: liquid and/or ice water content) in clouds is a fundamental parameter in cloud physics research. To experimentally measure liquid water content (LWC) on research aircraft, hot-wire probes are state of the art instruments (Ruskin, 1976; Nicholls et al., 1990). Until today the most commonly used hot-wire devices have been the Johnson-Williams probe, the DMT LWC-100, and the

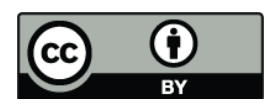

Correspondence to: A. Schwarzenboeck (a.schwarzenboeck@opgc.univ-bpclermont.fr)
King probe (King et al., 1978). These hot-wire probes are difficult to calibrate concerning their exact collection efficiencies. This is due to uncertainties on the one hand to predict the trajectories of hydrometeors having diameters below 5-10 $\mu \mathrm{m}$ (Korolev et al., 1998), and on the other hand due to incomplete evaporation and break-up during and after impaction of hydrometeors having diameters beyond $40 \mu \mathrm{m}$ (Biter et al., 1987; Strapp et al., 2003). Another type of instrument to measure cloud liquid water content is the Particle Volume Monitor (PVM) based on the principle of light diffusion by an ensemble of droplets (Gerber, 1993; Wendisch et al., 2002). A principal problem of the PVM, as for other optical instruments, is the exact knowledge of the sample volume and an eventual drift of the baseline.

Besides these direct measurements of LWC, estimates of the condensed water contents (LWC and IWC) can be derived by integrating the size spectra given from 1-D or 2D cloud probes. Examples for 1-D probes are the classical Forward Scattering Spectrometer Probe FSSP (Baumgardner, 1985) and its newer version called Cloud Droplet Probe CDP from DMT. Concerning 2-D probe imagery, classical instruments are the 2-D-P and 2-D-C (Knollenberg, 1981) probes, the newer Cloud and Precipitation Imaging Probes CIP and PIP, respectively, and also the Cloud Particle Imager CPI (Lawson, 1998). Another method is to entirely sample the condensed water content as done with the CVI (Counterflow Virtual Impactor) sampling technique (Ogren et al., 1985), evaporating all hydrometeors in an environment of dry air to finally derive the condensed water content for example with the technique of Lyman-a hygrometry (Ström et al., 1994). The CVI technology has been recently integrated into an oversize PMS canister, including hygrometer, by Droplet Measurement Technologies (DMT). Real-time information on cloud ice water content (IWC), however, stays a major challenge, particularly in mixed-phase clouds.

Published by Copernicus Publications on behalf of the European Geosciences Union. 
In 1998, Korolev et al. (1998) presented an extended characterisation of the Nevzorov instrument to overcome the lack of simultaneous and separate measurements of liquid and ice water contents. The Nevzorov probe which is a constanttemperature, hot-wire probe has been explicitly designed for rapid and simultaneous measurements of the ice and liquid water contents (phase discrimination) and thus, was extensively used on research aircraft for microphysical characterisation of mixed-phase clouds (Korolev, 2003) and in effective diameter studies (Korolev, 1999). It consists of two separate sensors for measurements of cloud liquid and total (ice plus liquid) water content, giving two linear equations for the variables LWC and IWC to be solved.

In principal, Korolev (1998) gave some insight in dry air baseline drift with airspeed, temperature, and pressure variations to explain possible offset variations for instance during vertical flight patterns. Moreover, collection efficiencies of the two separate sensors with respect to water and ice are discussed up to cloud particle (droplets, crystals) diameters of $25 \mu \mathrm{m}$. The probe performance is then discussed by means of measurement examples comparing the Nevzorov LWC and TWC data to the King and FSSP probe (Baumgardner, 1985) and also 2-D-C probe (Knollenberg, 1981) derived data. The correlation seems to be acceptable knowing the limited performance of the FSSP in view of larger ice crystals (Gardiner and Hallet, 1985) and the underestimation of water content by the 2-D-C due to the fact that below $150 \mu \mathrm{m}$ this probe is underestimating the crystal concentration (Gayet, 1993). The Nevzorov LWC and TWC sensors correlate quite well in small-droplet clouds. In mixed phase clouds, the TWC sensor measurement exceeds the LWC measurement due to its much higher efficiency in detecting ice particles, as expected due to the aerodynamic design of the capture volume. In large-droplet conditions of pure liquid clouds, the TWC measurement exceeds the LWC measurement, because the TWC sensor has much lower re-entrainment losses, and due to the fact that the existing collection efficiency assumptions for these probes in such conditions have not been well characterized to date.

Another study (Strapp, 2003) conducted in the NASA Icing Research Tunnel (IRT) presents results on Nevzorov LWC and TWC sensor retrievals of pure liquid droplet populations, as a function of the median volume diameter (MVD - also noted as DV50) which is the diameter in the LWC versus diameter distribution at which half of the liquid water is below, and the other half is above that diameter.

Whereas the Nevzorov TWC sensor matches the wind tunnel LWC (within WT LWC measurement accuracy), the Nevzorov LWC sensor significantly underestimates the WT LWC, particularly for larger median volume droplet diameters. The Nevzorov probe was also studied in the NRC Altitude Icing Wind Tunnel (AIWT) to assess differences in the response of LWC and TWC sensors of the probe with respect to ice (Korolev, 2002). These tests at the NRC high-speed icing tunnel have provided verification of the TWC recovery for small frozen droplets to an accuracy of approximately $10 \%-20 \%$ (Korolev, 2002). However, a series of tests at the Cox and Co. wind tunnel, using ice shaved from blocks to simulate ice particles, revealed that a fraction of these ice particles bounce out of the sample volumes of various hot wire devices, including the Nevzorov TWC probe, resulting in an underestimate of the IWC measurement (Emery et al., 2004; Strapp et al., 2005). Recently, a new design of the Nevzorov TWC sensor cone has been studied in the Cox wind tunnel (Korolev, 2008), where collection efficiencies with respect to ice particles of a new deep cone $\left(60^{\circ}\right)$ have been compared to those of the classical shallow cone $\left(120^{\circ}\right)$. It turns out that the classical shallow cone is considerably underestimating IWC due to ice particles bouncing off the TWC cone surface back into the air stream and being swept away.

The results presented here in this study, however, are mainly dedicated to improve our knowledge of the Nevzorov probe performance in large-droplet conditions of liquid/supercooled clouds, when drizzle size droplets are dominating LWC.

\section{Field project}

The geographic anomalies (high surface albedo, low solar elevation) in Polar regions were the principal motivation to initiate the international program Arctic Study of Tropospheric Aerosols, Clouds, and Radiation (ASTAR) to experimentally investigate the direct and indirect aerosol effects in the Arctic. The ASTAR project is particularly dedicated to investigate origin, transport pathways, vertical structure, physicochemical properties and radiatif impact of the tropospheric Arctic aerosol as well as related aerosol-cloud and cloudradiation interactions (particularly ice phase).

Within these objectives, aircraft in situ and remote sensing measurements on the two research aircraft Polar2 and Polar4 from Alfred-Wegener Institute (AWI), Germany, were conducted from the island of Spitsbergen (Norway) to study the microphysical and optical properties of Arctic aerosol and supercooled to mixed-phase clouds.

Cloud in situ measurements were performed onboard Polar2 using a Nevzorov probe (Korolev, 1998), the Polar Nephelometer (Gayet, 1997), a Cloud Particle Imager (Lawson, 1998 and 2001), and classical FSSP and 2-D-C PMS probes. In total 14 cloud flights have been performed on Polar2 during the entire ASTAR 2004 flight campaign for detailed (cf. Table 1) microphysical and optical cloud in situ studies. In particular, the campaign yielded observations of iced nimbostratus, altostratus, and stratus clouds which are often found in the Arctic boundary layer. Despite just slightly negative temperatures between 0 and $-20^{\circ} \mathrm{C}$ encountered during Polar-2 flight missions, the ice phase (mixed phase) was observed quite frequently. Simultaneous research flights were performed on the Polar4 aircraft to characterise the aerosol particles. During the entire period aerosol particle 
Table 1. Summary of cloud in situ instrumentation mounted on Polar-2 research aircraft during ASTAR 2004.

\begin{tabular}{llc}
\hline Instrument & Measurement parameter & Range \\
\hline $\begin{array}{l}\text { Polar } \\
\text { Nephelometer }\end{array}$ & $\begin{array}{l}\text { Scattering phase function } \\
\text { (asymmetry parameter, } \\
\text { extinction coefficient,...) }\end{array}$ & $3-800 \mu \mathrm{m}$ \\
CPI & $\begin{array}{l}\text { Cloud particle microphysical and } \\
\text { morphological properties }\end{array}$ & D $>10 \mu \mathrm{m}$ \\
Nevzorov & Ice and liquid water content & $0 .-1 . \mathrm{g} / \mathrm{m}^{3}$ \\
PMS FSSP & Cloud particle size distribution & $3-95 \mu \mathrm{m}$ \\
PMS 2-D-C & Cloud particle size distribution & $25-800 \mu \mathrm{m}$ \\
\hline
\end{tabular}

concentrations, measured with a CPC 3010 (measuring particles larger $11 \mathrm{~nm}$ ), have been very low ( $<300$ aerosol particles per $\mathrm{cm}^{3}$ ). These clean conditions should have been at the origin of frequently observed supercooled drizzle size droplets (cf. Fig. 1), up to some hundreds of $\mu \mathrm{m}$ in diameter even in very shallow stratus type Arctic cloud layers ( $\sim 500 \mathrm{~m}$ between cloud base and cloud top). In addition, lowest IN concentrations (coming along with low aerosol concentrations) may slow down considerably the ice related processes including nucleation, multiplication, and precipitation. Consequently, only little precipitation was observed during ASTAR 2004. Moreover, onboard nadir looking lidar observations which revealed specific cloud features, i.e. stratiform layers and ice crystals precipitating from beyond (Stachlewska et al., 2006; Gayet et al., 2007) determined flight levels for subsequent cloud in situ measurements. The cloud in situ measurements thus could confirm the presence of the "feeder-seeder" mechanism, initiating the ice phase in low level stratocumulus cloud layers at slightly negative temperatures.

\section{Instrumentation: Nevzorov probe and other cloud in situ instruments}

The instrumental payload used for the cloud in situ studies on Polar-2 (Dornier-228) comprised an extensive, state-ofthe art set of cloud microphysical/optical instruments including particularly: (i) a Polar Nephelometer for the measurement of the scattering phase function of ice particles, (ii) a Cloud Particle Imager (CPI) recording digitised cloud particle images at high pixel resolution $(2.3 \mu \mathrm{m})$, and (iii) the Nevzorov probe for the measurement of the liquid and ice water content in supercooled and mixed-phase clouds. The main focus in this study will be given to the performance of the Nevzorov probe. The Nevzorov sensors have been are mounted the probe pylon on the right side of the fuselage about three meters behind the nose of Polar2 and at a distance of roughly $25 \mathrm{~cm}$ from the aircraft skin. The particle

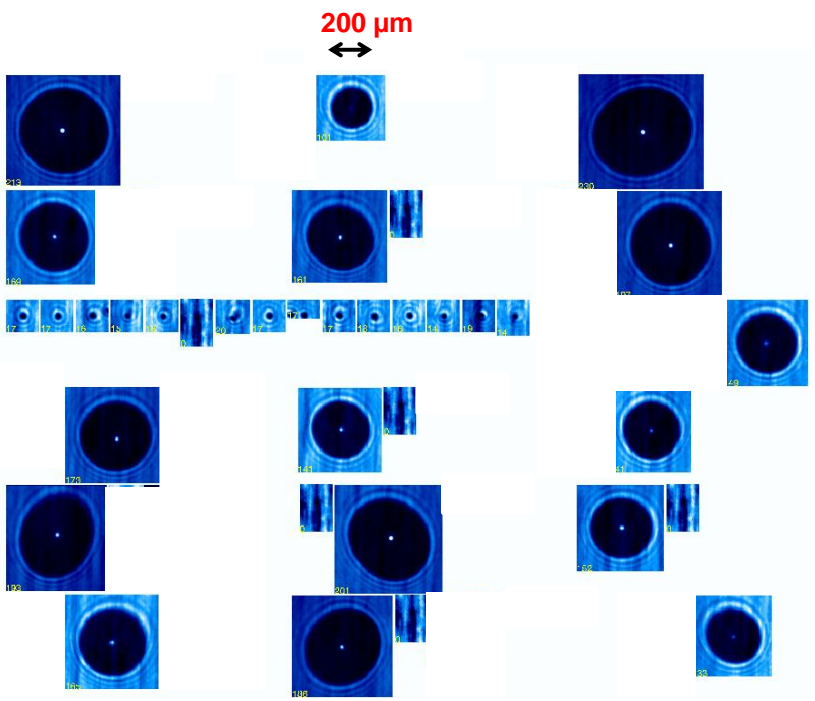

Fig. 1. Presence of drizzle size droplets $(100-500 \mu \mathrm{m})$ in stratus type Arctic clouds during ASTAR 2004.

trajectories are not perturbed by other installations upstream the probe. Even though we cannot completely rule out depletion or enrichment effects at the position of the Nevzorov probe (aircraft flight trajectory related wind vector), at least both sensors (TWC and LWC) have been exposed to identical droplet sizes.

The two TWC and LWC sensors of the Nevzorov hot-wire probe (kept at constant temperature) are composed each of a reference and a collector/sample zone, whereby the reference zone will not undergo cloud particle impaction. Due to cloud particle impaction (and thus evaporation) the sample zone experiences heat loss, which has to be compensated, thus, making the hotwire probe a constant temperature probe. The necessary power to apply to the sensors is related to LWC and TWC, both functions of electrical powers $P_{\text {LWC }}$ and $P_{\text {TWC }}$, sensor surfaces $S_{\mathrm{LWC}}$ and $S_{\mathrm{TWC}}$, the velocity $\mathrm{U}$, and the four collection efficiencies of LWC and TWC sensors with respect to water droplets and ice crystals. In addition, the known sensor resistances $R_{\mathrm{LWC}}$ and $R_{\mathrm{TWC}}$ appear in the electrical powers

$P_{\mathrm{LWC}}=\frac{V_{\mathrm{LWC}}{ }^{2}}{R_{\mathrm{LWC}}}$

and

$P_{\mathrm{TWC}}=\frac{V_{\mathrm{TWC}}{ }^{2}}{R_{\mathrm{TWC}}}$

supplied to the sensors via the voltages $V_{\text {LWC }}$ and $V_{\text {TWC }}$. Combining $P_{\mathrm{LWC}}$ and $P_{\mathrm{TWC}}$ supplied to both sensors gives one single solution for LWC and IWC (Korolev, 1998):

$$
\mathrm{LWC}=\frac{P_{\mathrm{LWC}}-\frac{P_{\mathrm{TWC}} \times \varepsilon_{\mathrm{LWC}, \text { crystal } \times} \times S_{\mathrm{LWC}}}{\varepsilon_{\mathrm{TWC}, \text { crystals }} \times S_{\mathrm{TWC}}}}{L_{\mathrm{V}} \times S_{\mathrm{LWC}} \times U \times\left(\varepsilon_{\mathrm{LWC}, \text { droplets }}-\frac{\varepsilon_{\mathrm{LWC}, \text { crystals }} \times \varepsilon_{\mathrm{TWC}, \text { droplets }}}{\varepsilon_{\mathrm{TWC}, \text { crystals }}}\right)},
$$


and

$$
\mathrm{IWC}=\frac{P_{\mathrm{TWC}}-\frac{P_{\mathrm{LWC}} \times \varepsilon_{\mathrm{TWC}, \text { droplets }} \times S_{\mathrm{TWC}}}{\varepsilon_{\mathrm{LWC}, \text { droplets }} \times S_{\mathrm{LWC}}}}{\left(L_{\mathrm{f}}+L_{\mathrm{V}}\right) \times S_{\mathrm{TWC}} \times U \times\left(\varepsilon_{\mathrm{TWC}, \text { crystals }}-\frac{\varepsilon_{\mathrm{LWC}, \text { crystals }} \times \varepsilon_{\mathrm{TWC}, \text { droplets }}}{\varepsilon_{\mathrm{LWC}, \text { droplets }}}\right)} .
$$

The most crucial question then is the exact knowledge of TWC and LWC sensor efficiencies, depending on particle phase (droplets, crystals) and size. $\mathrm{L}_{\mathrm{v}}$ and $\mathrm{L}_{\mathrm{f}}$ denote latent heat of vaporization and fusion, respectively. Since during ASTAR 2004 we encountered pure supercooled and mixed phase conditions, but no pure ice phase clouds, we will focus the discussion of the Nevzorov probe response to flights (flight sequences) of pure liquid cloud phase in the Arctic environment. In this way we can skip the two sensor efficiencies related to ice ( $\varepsilon_{\mathrm{LWC}, \text { crystals }}$ and $\left.\varepsilon_{\mathrm{TWC} \text {,crystals }}\right)$, in order to solely study those two efficiencies related solely to droplets: $\varepsilon_{\mathrm{LWC}, \text { droplets }}$ and $\varepsilon_{\mathrm{TWC}, \text { droplets }}$.

Thus, when ice is absent the TWC and LWC sensors individually give the liquid water content:

$\mathrm{LWC}_{(\text {LWCsensor })}=\frac{P_{\mathrm{LWC}}}{\varepsilon_{\mathrm{LWC}, \text { droplets }} \times L_{\mathrm{V}} \times S_{\mathrm{LWC}} \times U}$

from the LWC sensor and

$\mathrm{LWC}_{(\mathrm{TWC} \text { (sensor) }}=\frac{P_{\mathrm{TWC}}}{\varepsilon_{\mathrm{TWC}, \text { droplets }} \times L_{\mathrm{V}} \times S_{\mathrm{TWC}} \times U}$

from the TWC sensor.

Both equations should give identical amounts of LWC in pure liquid cloud, where liquid water content depends on aircraft velocity $\mathrm{U}$, the electrical powers $\mathrm{P}_{\mathrm{LWC}}$ or $\mathrm{P}_{\mathrm{TWC}}$ supplied, and the collection efficiency of LWC and TWC sensors with respect to water droplets:

$\mathrm{LWC}=f\left(P_{\mathrm{LWC}}, U, \varepsilon_{\mathrm{LWC}, \text { droplets }}\right)=f\left(P_{\mathrm{TWC}}, U, \varepsilon_{\mathrm{TWC}, \text { droplets }}\right)$.

\section{Description of the dataset and data processing}

\subsection{Cloud presence criterion}

Ideally the Nevzorov probe signals should have very small to zero offsets, achievable at constant flight levels. Before entering a cloud the collector signal has to be adjusted to the reference signal to operate the sensors at zero offsets. The signal ideally returns to zero after leaving the cloud at the same level, which indicates a zero offset for the entire leg at that flight level. To avoid truncated slightly negative signals it may be even worthwhile to operate the Nevzorov probe with a very small positive offset. In addition, during the ASTAR experiment the flight pattern consisted sometimes of climbs and descents in clouds, which made it difficult to achieve the objective of zero offset. Since for the Nevzorov data it is necessary to subtract the offset in both raw signals, before calculating the condensed water contents LWC and IWC, our idea was to benefit from simultaneous measurement signals of other fast and highly sensitive cloud probes, like the Polar Nephelometer, to define precisely cloud presence (Fig. 2),

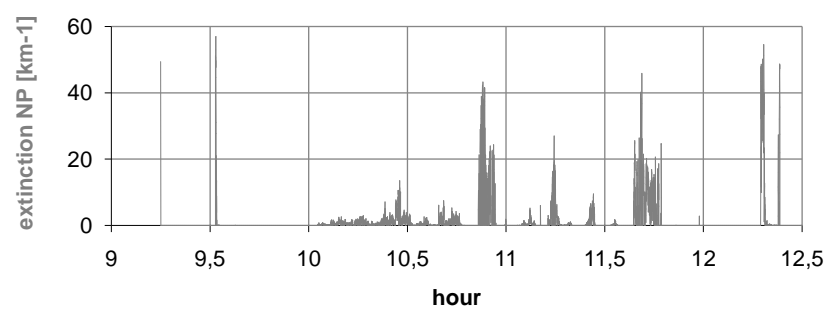

Fig. 2. Definition of cloud presence via the extinction coefficient calculated from the Polar Nephelometer (22 May 2004).

such that experimentally we can calculate the offsets of Nevzorov probe raw signals for clear sky passages and interpolate the offset within cloud sequences.

\subsection{Offset correction}

The Nevzorov offset has to be deduced from the measured signal to get the raw cloud related signal. Figure 3 shows an example (corresponding to Nephelometer cloud detection in Fig. 2) of an unusually high offset caught during a flight. Due to the fact that the electrical power $P$ supplied to the two sensors is proportional to the square of the corresponding voltages $V$, the pure cloud related signal $V_{\text {cloud }}$ is calculated from the total raw signal $V_{\text {raw }}$ and the offset signal $V_{\text {offset }}$ in the following way:

$V_{\text {cloud }}=\sqrt{V_{\text {raw } 2}-V_{\text {offset }} 2}$.

\section{Results for the Nevzorov probe response to arctic clouds}

\subsection{Discussion of the sensor efficiencies in liquid clouds}

In order to get an idea of the variation of droplet spectra observed during the ASTAR campaign, Fig. 4 presents averaged number size distributions for some of the flights. In particular, the large-droplet condition is often dominating the number size distributions. The collection efficiency of the Nevzorov TWC sensor for drizzle-size droplets is close to unity, as was demonstrated in wind tunnel testing at the NASA Icing Research Tunnel (Strapp et al., 2002). Furthermore, Strapp et al. (2003) presented a detailed study of Nevzorov LWC and TWC sensor response with respect to large-droplet conditions (Fig. 5). The study was conducted in the NASA Glenn Icing Research Tunnel (IRT) in 1998. The Nevzorov LWC sensor with cylindrical sensor wire of $1.8 \mathrm{~mm}$ in diameter was found to measure solely $50 \%$ of the LWC at a median volume diameter of approximately $200 \mu \mathrm{m}$. Similar results were first shown by Biter et al. (1987) for the King probe, another cylindrical hot wire like the Nevzorov LWC, and for various other cylindrical hot wires by Strapp et al. (2003). The Nevzorov TWC sensor 


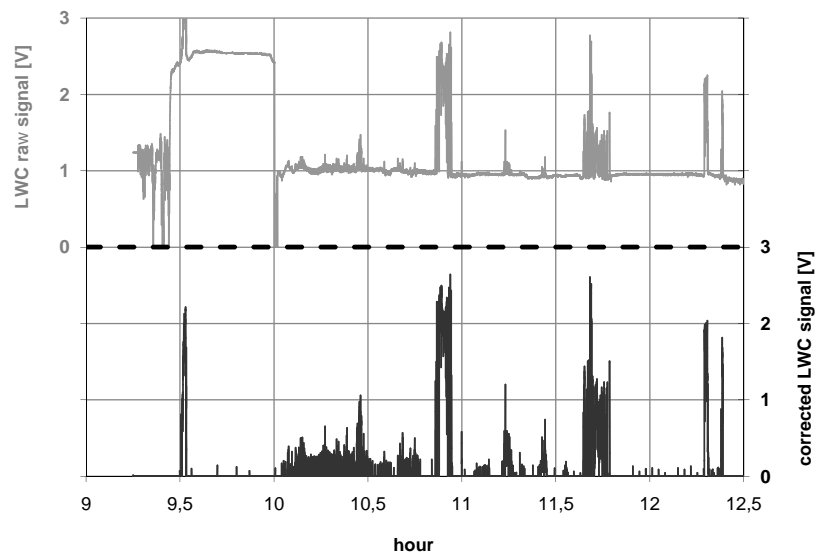

Fig. 3. Offset subtraction for a high offset example of the LWC sensor (22 May 2004).

was found to agree within $+/-20 \%$ of tunnel reference LWC across the entire tested range of MVD within 11-236 $\mu \mathrm{m}$. According to Strapp (2003) the accuracy of IRT tunnel LWC is estimated to be $5 \%$ for populations of small droplets and $20 \%$ for populations of large drops. The findings that LWC retrievals from Nevzorov TWC sensor throughout all droplet MVD are higher than IRT wind tunnel LWC measurements should indicate that the Nevzorov TWC sensor may not miss a significant amount of LWC even within droplet populations showing large values for MVD $(\sim 200 \mu \mathrm{m})$. The Nevzorov TWC sensor is therefore considered the most accurate hotwire estimate of LWC in large-droplet conditions of pure water clouds, whereas LWC sensor efficiencies remain unclear in these conditions. Thus, we will focus here primarily on the Nevzorov sensor efficiencies with respect to water, knowing that the ASTAR 2004 cloud flights sampled either supercooled or mixed phase clouds. The phase recognition of clouds was performed using the simultaneously operated Cloud Particle Imager CPI. For subsequent data analysis of pure liquid clouds or liquid cloud sequences, the Nevzorov data were analyzed when the CPI detected pure liquid phase.

The Nevzorov LWC and TWC sensors correlate quite well in small-droplet liquid clouds where $\varepsilon_{\mathrm{LWC} \text {,droplets }}$ and $\varepsilon_{\text {TWC,droplets }}$ efficiencies are close to one. Taking the above Eqs. (5) and (6) of calculated liquid water contents from LWC sensor and TWC sensor, and imposing that $\mathrm{LWC}_{(\mathrm{LWCsensor})}=\mathrm{LWC}_{\text {(TWCsensor) }}$ for whatever population of droplet sizes, leads to the ratio of sensor efficiencies related to the raw signals:

$$
\begin{aligned}
\frac{\varepsilon_{\mathrm{LWC}, \text { droplets }}}{\varepsilon_{\mathrm{TWC}, \text { droplets }}} & =\frac{\mathrm{P}_{\mathrm{LWC}} \times \mathrm{S}_{\mathrm{TWC}}}{P_{\mathrm{TWC}} \times S_{\mathrm{LWC}}}=\frac{V_{\mathrm{LWC}^{2}} \times R_{\mathrm{TWC}} \times S_{\mathrm{TWC}}}{V_{\mathrm{TWC}}^{2} \times S_{\mathrm{LWC}} \times R_{\mathrm{LWC}}} \\
& =1.595 \times \frac{V_{\mathrm{LWC}^{2}}}{V_{\mathrm{TWC}^{2}}} .
\end{aligned}
$$

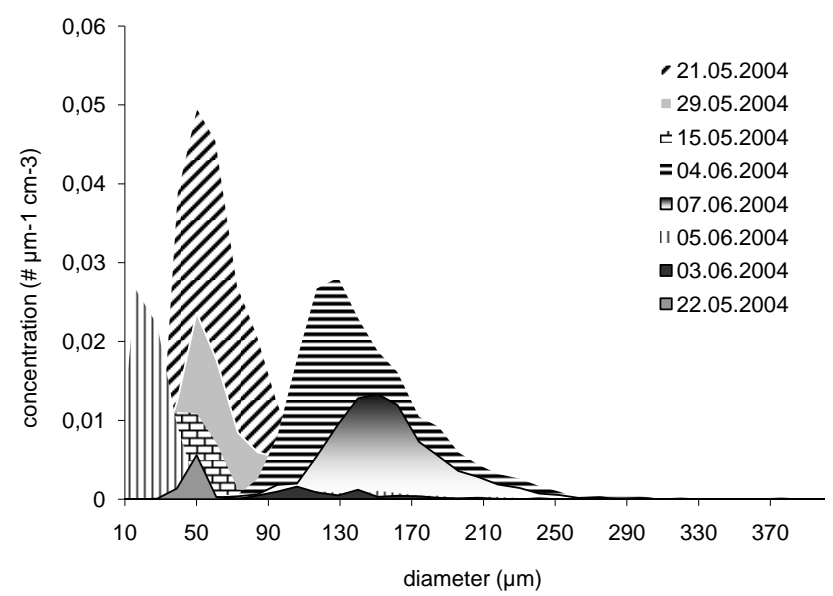

Fig. 4. Variation of droplet size spectra during ASTAR 2004.

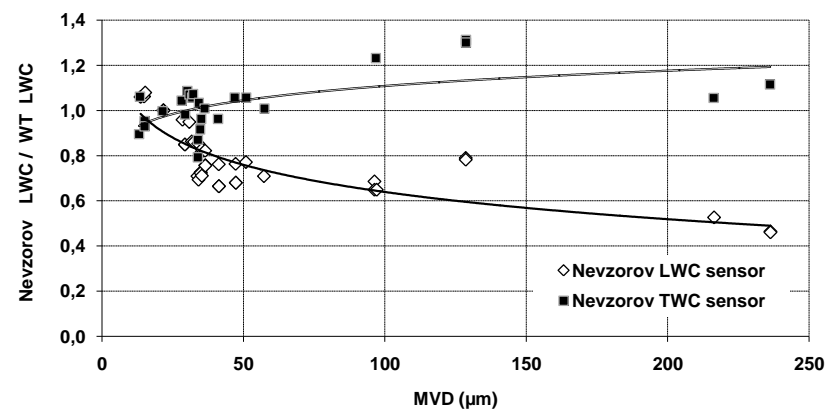

Fig. 5. Findings of Strapp et al. (2003) for the Nevzorov TWC and LWC sensor behaviour with respect to the wind tunnel reference LWC in pure liquid clouds.

The factor 1.595 has been calculated from known instrumental parameters of sensor surfaces and electrical resistances of the respective Nevzorov probe used during ASTAR 2004. Plotting $1.595 \times V_{\mathrm{LWC}}^{2}$ against $V_{\mathrm{TWC}}^{2}$ for all measured ASTAR data in pure liquid clouds, reveals that $V_{\text {TWC }}^{2}$ is in general dominating $1.595 \times V_{\mathrm{LWC}}^{2}$, thus, demonstrating that the liquid water recovery from TWC sensor is higher than the recovery from LWC sensor (Fig. 6). Merely at lower values of raw signals it nevertheless happens that the LWC signal slightly dominates the TWC sensor signal (data points above the theoretical line of equal LWC and TWC sensor efficiencies with respect to water). To better understand differences in efficiency of water recovery of both sensors, we have to relate the LWC recovery to the respective ensemble of sampled cloud droplets. For a more detailed analysis of the above results, the ratios of the two efficiencies $\varepsilon_{\mathrm{LWC} \text {,droplets }}$ and $\varepsilon_{\mathrm{TWC} \text {,droplets }}$ of LWC and TWC sensors are studied as a function of the droplet size distribution, that we try to best parameterize using an adequate cloud particle diameter. Strapp et al. (2003) have chosen in their efficiency 
study of the Nevzorov probe the median volume diameter MVD as the spectrum reference diameter, to parameterize the IRT wind tunnel droplet populations, where MVD is defined as the diameter out of the droplet spectrum at which $50 \%$ of the water is below, and $50 \%$ is above that diameter MVD:

$$
\int_{0}^{\text {MVD }} D^{3} N(D) d D=\int_{\text {MVD }}^{D_{\max }} D^{3} N(D) d D .
$$

MVD is particularly used to describe artificially produced droplet populations, thus, representing an adequate diameter parameterization for the droplet populations sprayed into the IRT tunnel. Whereas droplet distributions generated in a wind tunnel are often characterized by long tails in the "bell" shaped mono-modal distributions, these artificial distributions lack the typical distinct mode in the small-droplet part seen usually in atmospheric distributions. To best parameterize natural droplet populations (mono-modal and particularly bi-modal) encountered during ASTAR (this study), we have chosen the volume-weighted mean diameter VMD defined as

$$
\mathrm{VMD}=\frac{\int_{0}^{D_{\max }} D^{4} N(D) d D}{\int_{0}^{D_{\max }} D^{3} N(D) d D} .
$$

Compared to MVD used in the IRT study, VMD should be less sensitive to the presence of observed small droplets coexisting with large drops in the drizzle size range, most important for this study. Furthermore, when comparing this study to the findings presented by Strapp et al. (2003), we have to take into account that VMD should slightly exceed MVD calculations (by $0-10 \%$ for the droplet size distributions measured during ASTAR). In addition, we have to state that VMD (also MVD) estimation can be difficult with common probes. The difficulty to derive an absolute estimate of the uncertainty in calculating cloud particle VMD (or MVD) for measurements of (i) a specific cloud probe, (ii) a particular combination of several probes, and (iii) when using/comparing different cloud probes arises from individual probe performances/characteristics, from data processing software, and from other probe and/or operator specific parameters. This could be causing some of the differences between the results presented by Strapp et al. (2003) and the results presented here (Fig. 7). Putting together all 14 scientific research flights within the ASTAR project, Fig. 7 shows plotted ratios of the two efficiencies $\varepsilon_{\mathrm{LWC}}$,droplets and $\varepsilon_{\mathrm{TWC}}$,droplets of LWC and TWC sensors during pure liquid cloud sequences as a function of VMD. As a result we observe that for very small droplet diameters up to roughly 20 $40 \mu \mathrm{m}$ the LWC sensor seems to be more efficient than the TWC sensor, which is due to the fact that the large TWC cone represents an important obstacle for the cloud particles which

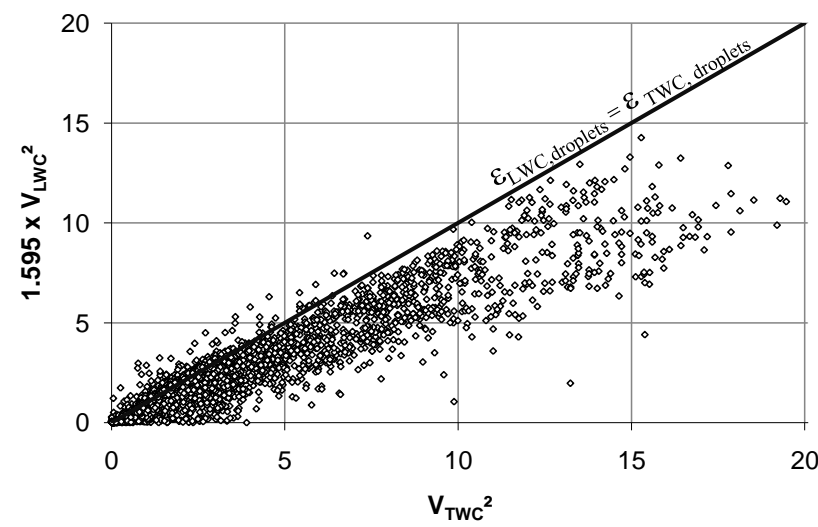

Fig. 6. "Correlation" of LWC and TWC sensor voltages in pure liquid clouds, a theoretical line of equal sensor efficiencies $\varepsilon_{\text {LWC, droplets }}=\varepsilon_{\text {TWC, droplets }}$, is added.

begin quite early to curve around the sensor and thus don't impact as efficient as on the smaller LWC sensor obstacle. Droplet sizes beyond several tens of micrometers, however, should impact more efficiently on the TWC sensor but less efficiently on the LWC sensor with increasing droplet diameters. It is important to recall that for the two previous figures we have chosen only liquid cloud sequences automatically derived from CPI data of the entire ASTAR 2004 campaign. All data were averaged over $10 \mathrm{~s}$ intervals to avoid larger statistical fluctuations. The signal averaging of FSSP, CPI, 2 D-C and Nevzorov data was chosen since the instruments were not mounted side by side. In addition, the evaporation of droplets on the surface of hot wire probes is not instantaneous, leading to a slightly delayed and smoothed signal as a function of droplet diameters. The $y$-axis error bars reflect the standard deviation of the $10 \mathrm{~s}$ average calculations of the ratio of the sensor efficiencies. Possibly an additional error may be due to small gain differences between the LWC and TWC probe, since we cannot measure the calibration constants perfectly, so there might be some possibly small linear effect.

To interpret the above results we recall that Korolev (1998) presented theoretical calculations of the collection efficiencies with respect to liquid droplets of (i) the cylindrical LWC sensor $\varepsilon_{\text {LWC,droplets }}$ based on Voloshchuk (1971) and (ii) of the conical TWC sensor efficiency $\varepsilon_{\mathrm{TWC}}$,droplets based on experimental studies (Nevzorov, 1983). Moreover Strapp et al. (2003) presented collision efficiency estimates for a representation of the Nevzorov TWC sensor, using the NASA LEWICE model, where $\varepsilon_{\mathrm{TWC}}$,droplets deviates little from results shown in Korolev (1998). In Korolev's work the two efficiencies $\varepsilon_{\mathrm{LWC}}$,droplets and $\varepsilon_{\mathrm{TWC}}$,droplets were presented as a function of effective diameter $\mathrm{D}_{\text {eff }}$ limited to diameters up to $25 \mu \mathrm{m}$ and calculated according to:

$\varepsilon_{\text {SENSOR,droplets }}=\frac{D_{\text {eff }}{ }^{2}}{D_{\text {eff }}{ }^{2}+D_{0}{ }^{2}}$ 


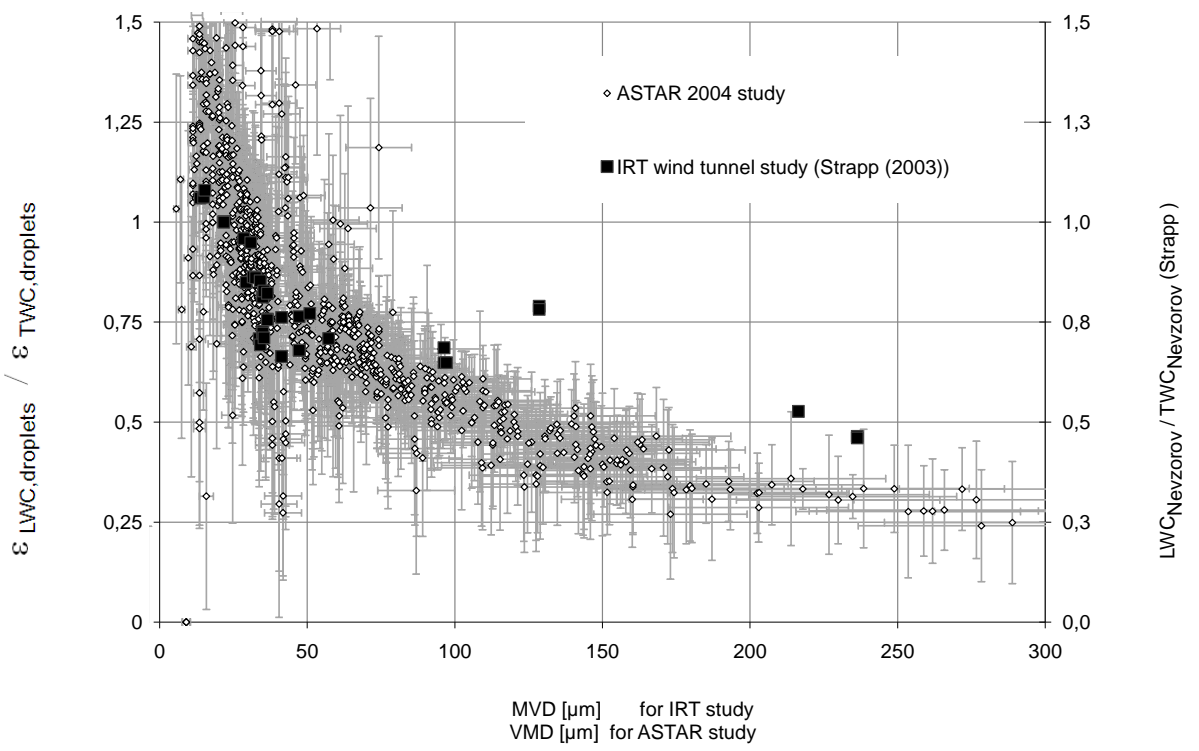

Fig. 7. Efficiency ratio of LWC to TWC Nevzorov sensors with respect to pure water droplets. In addition, ratio of Nevzorov LWC over TWC from Strapp (2003).

with $D_{0}=7.5$ for TWC sensor and $D_{0}=1.7$ for the LWC sensor, respectively, for an aircraft velocity in the order of $100 \mathrm{~m} / \mathrm{s}$. For droplet diameters beyond $25 \mu \mathrm{m}, \varepsilon_{\mathrm{TWC}}$,droplets should approach the ideal value of 1 , whereas $\varepsilon_{\mathrm{LWC}}$,droplets may decrease to values significantly smaller than 1 , at least for diameters of several hundreds of $\mu \mathrm{m}$ (Korolev, 1998). An exact behaviour of $\varepsilon_{\mathrm{LWC}}$,droplets curve has not been discussed yet and will be determined subsequently in this study. Not knowing the exact size distributions that led to (i) deduced MVD in the wind tunnel study of Strapp et al. (2003) and (ii) the effective diameters in the $\varepsilon_{\text {TWC,droplets }}$ efficiency calibration study of Nevzorov (1983), we make the assumption that these experimental spectra were "bell" shaped distributions. The assumption that

$\frac{D_{84}}{D_{50}}=\frac{D_{50}}{D_{16}}=\sigma$

(for considered lognormal distributions), then translates (within error bars calculated for $1.5<\sigma<2.0$ ) the effective droplet diameters from Nevzorov (1983) into MVD and VMD (Martin et al., 1994; Hinds, 1999). Knowing the droplet size distribution, median volume and volumeweighted mean diameters can be calculated and converted into each other. In addition, an extrapolation of $\varepsilon_{\mathrm{TWC}}$,droplets of the conical TWC sensor to values approaching 1 for cloud droplet effective diameters far above $25 \mu \mathrm{m}$ has been suggested by Korolev (1998). This suggestion has been supported by Strapp (2003) due to measurements in the IRT wind tunnel, where the Nevzorov TWC sensor measurements are slightly, but systematically, exceeding the tunnel reference LWC measurements (as well for small-droplet as for large-droplet conditions) within the estimated accu- racy of wind tunnel reference LWC measurements. Within the assumptions of the above mentioned extrapolation, this allows to give an estimate of the least known efficiency $\varepsilon_{\text {LWC,droplets. }}$ The procedure is presented in Fig. 8 where the efficiency ratio from Fig. 7 has been multiplied by the

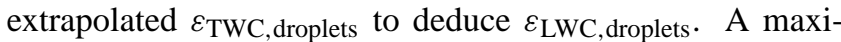
mum in $\varepsilon_{\mathrm{LWC}}$,droplets is reached roughly around $20-30 \mu \mathrm{m}$, indicating that droplets smaller than $20-30 \mu \mathrm{m}$ partly tend to curve around the LWC sensor, whereas larger ones impact with decreasing efficiencies related to a loss in droplet mass. $\varepsilon_{\text {LWC,droplets }}$ rapidly starts to decrease (with increasing droplet size) beginning at droplet sizes beyond 30-40 $\mu \mathrm{m}$.

This study therefore suggests for VMD diameters beyond $25 \mu \mathrm{m}$ the following parametrization for $\varepsilon_{\mathrm{LWC} \text {,droplets }}$ of the Nevzorov probe:

$\varepsilon_{\text {LWC,droplets }}(\mathrm{VMD})=\frac{a_{0}}{\left[1+\left\{\frac{V M D-a_{1}}{a_{2}}\right\}^{2} \times\left\{2^{\frac{1}{a_{3}}}-1\right\}\right]^{a_{3}}}$

with $a_{0}=0.98, a_{1}=20, a_{2}=90, a_{3}=0.26$;

\subsection{Application of above calculated $\varepsilon_{L W C}$,droplets efficien- cies to calculate IWC and LWC in observed mixed phase clouds during ASTAR 2004}

Accurate determination of the liquid VMD from particle probes in mixed-phase conditions is exceedingly difficult. The only reliable means is based on the CPI distributions, and therein the separation of the ice particles from the water droplets. The CPI images were preprocessed using the software (Lefèvre, 2007) developed at the Laboratoire de Météorologie Physique (LaMP). More specifically, we added, to the original automated habit classification, three 


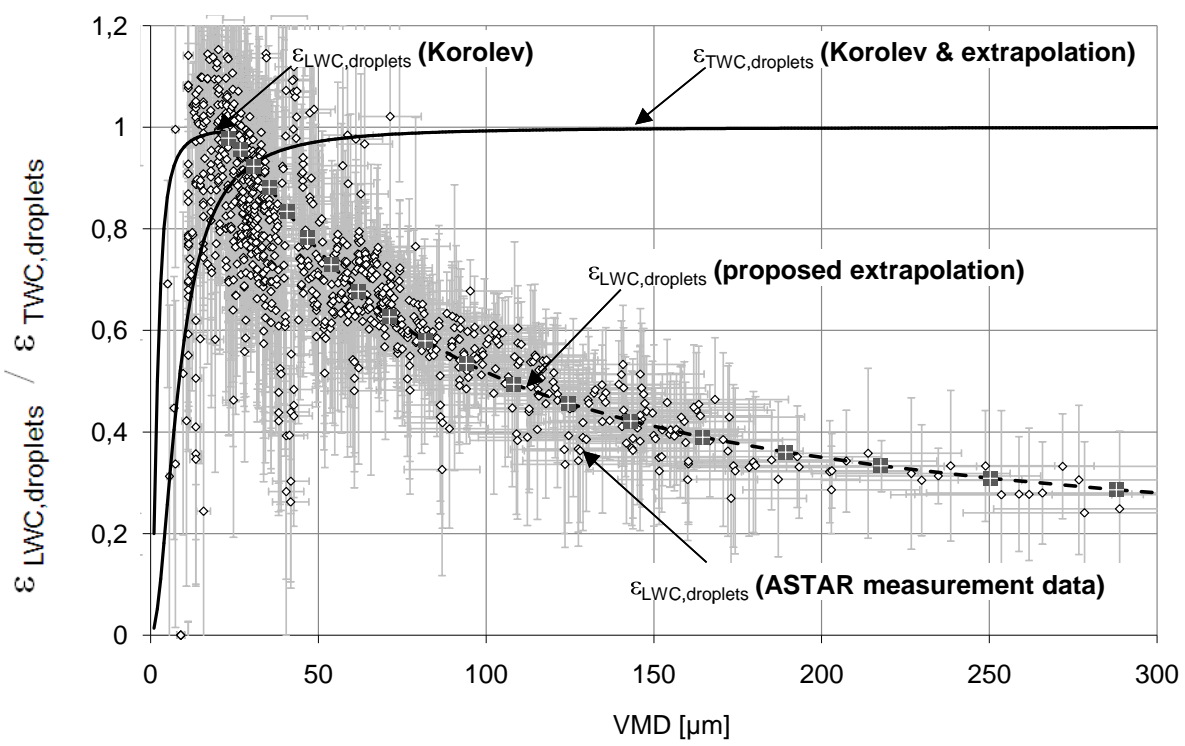

Fig. 8. Derived LWC sensor efficiency $\varepsilon_{\text {LWC,droplets }}$ assuming the TWC sensor efficiency $\varepsilon_{\text {TWC,droplets }}$ from Korolev (1998) including extrapolation of $\varepsilon_{\mathrm{TWC}}$,droplets for large-droplet conditions.

habit types and used our algorithm to evaluate the effective sampling volume of the CPI (Lefèvre, 2007). To be able to calculate IWC and LWC in mixed phase clouds for the Nevzorov probe, thus, using size and phase dependent Nevzorov probe efficiencies, we have to determine and calculate phase and MVD, respectively, from size distributions for liquid and solid cloud particles. The most critical point is the correct phase discrimination (surface roughness) for spherical particles, which is more difficult to determine for smallest spherical particles. However, we are convinced that beyond a diameter of $50 \mu \mathrm{m}$ we can be quite sure from CPI images about the phase (liquid or ice) of spherical particles captured on CPI images.

For further analysis of the Nevzorov data within real mixed phase Arctic clouds sampled during ASTAR 2004, efficiencies $\varepsilon_{\mathrm{TWC}}$,droplets and $\varepsilon_{\mathrm{LWC}}$,droplets are applied as extrapolated and calculated above, respectively. Furthermore, the efficiency $\varepsilon_{\mathrm{LWC} \text {,crystals }}$ is estimated to be approximately 0.11 (Korolev, 1998), explaining a slight reaction of the LWC sensor with respect to impacting ice crystals, which then bounce off. Unfortunately, the value of 0.11 is only a rough estimate since $\varepsilon_{\text {LWC,crystals }}$ will certainly depend on crystal size and probably shape, however, we have no other estimation than was given by the manufacturer. Finally, the effi-

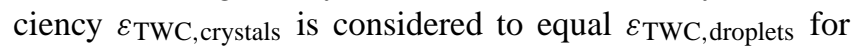
identical median mass aerodynamic diameters (thus, including the particle density), to take into account ice particles with estimated density of 0.9 . An eventual discussion of sensor efficiency variations with ice crystal shape seems to be complicated and is beyond the scope of this study. In addition, Korolev (2008) presented evidence that ice particles may significantly bounce off from the surface of the Nev- zorov TWC sensor cone (and other hot-wire sensor geometries). They demonstrated that $\varepsilon_{\mathrm{TWC}}$,crystals of the commercial shallow $\left(120^{\circ}\right)$ TWC cone of the Nevzorov Probe could be up to 3 times smaller than $\varepsilon_{\text {TWC,crystals }}$ for a modified deep cone $\left(60^{\circ}\right)$ of the same sensor. Due to the lack of ice crystal calibration standards a detailed investigation of the poor IWC recovery by the TWC shallow cone is still under discussion. Future work will have to detail dependencies of $\varepsilon_{\text {TWC,crystals, }}$, that may exist with respect to cloud phase (mixed phase, pure ice phase) and as a function of crystal diameter (VMD, MVD). We decided here not to apply a simple scaling factor of 3 for $\varepsilon_{\mathrm{TWC}, \text { crystals }}$ for several reasons: first of all we have been measuring in mixed phase clouds, compared to pure ice clouds in wind tunnel and in natural cloud studies (Korolev et al., 2008). Second, we should learn more about correlations between the crystal habit/size and ice water recovery of the TWC Nevzorov probe. Moreover, retrieved IWC (and TWC) from the Nevzorov shallow cone during ASTAR has been exceeding IWC values presented in the Korolev et al. study by a factor of at least two, such that we would have to extrapolate the Korolev et al. findings to larger IWC contents, which might be tricky. Thus, the above assumed sensor efficiencies with respect to water (high reliability) and ice (significant lack of knowledge) as a function of diameter, allow at least under the described efficiency assumptions to estimate simultaneously IWC and LWC of Arctic mixed phase clouds as described in Sect. 3.

Figure 9 presents the results of calculated IWC and LWC in terms of the fraction of ice water content IWC out of total condensed water TWC $(\mathrm{TWC}=\mathrm{LWC}+\mathrm{IWC})$ plottet against the asymmetry parameter. The asymmetry parameter $g$ is deduced from the scattering phase function of the Polar 


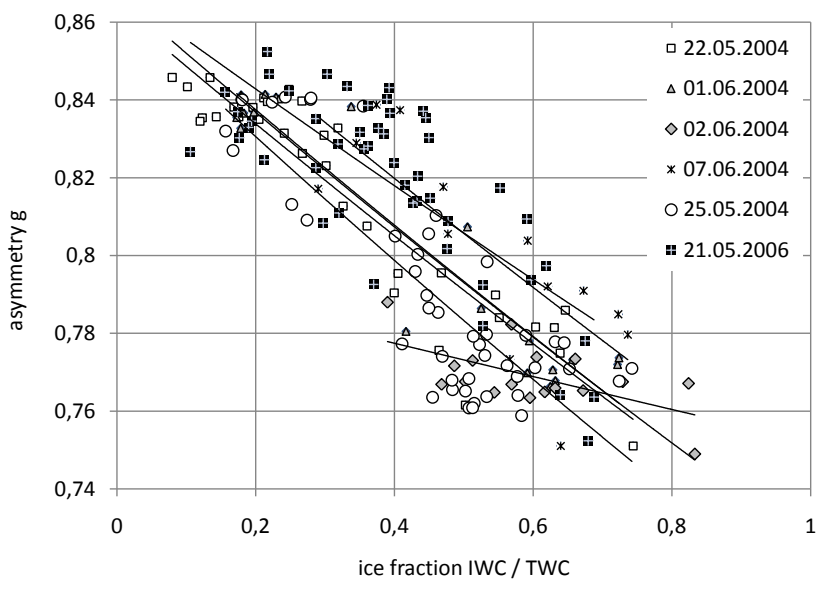

Fig. 9. Cloud ice fraction related to asymmetry parameter deduced from scattering phase functions of the Polar Nephelometer.

Nephelometer (Gayet, 1997) and gives an indication of the mean cosine of light scattered in a two-dimensional plane from cloud particles. The scattering characteristics (asymmetry factor etc.) vary with respect to cloud phase, cloud particle size, ice crystal shape, surface roughness and others. Theoretically the asymmetry factor is comprised between 0 for isotropic scattering and 1 in case that the light is not at all deviated with respect to the incident direction of light. Garrett et al. (2001) showed a quite good correlation between IWC number fraction and asymmetry parameter. Similar to Garret's results we obtain approximately 0.85 for the asymmetry factor of smallest ice mass fractions (10-20\%) in mixed phase clouds and 0.74 for highest observed ice fractions (80\%) during the ASTAR 2004 campaign. There is clear correlation between $g$ and the ice fraction for all presented flights, however, the correlation coefficient is quite low due to certainly complicated relations between asymmetry factor and crystal size, shape, surface roughness, etc. The parameterised efficiencies for the two sensors, in particular $\varepsilon_{\mathrm{LWC} \text {,droplets, }}$, seem to produce a consistent ratio between ice and total condensed water calculated from the Nevzorov probe that correlates quite well with the asymmetry factor.

\section{Conclusions}

Within the frame of 14 scientific cloud flights during the ASTAR 2004 measurement campaign, this study represents an extended analysis of the Nevzorov probe response in Arctic supercooled and mixed phase clouds. Knowing that the efficiencies of the LWC and TWC sensors of the Nevzorov probe have not yet been adequately characterized beyond cloud particle diameters of $25 \mu \mathrm{m}$, this study contributes to confine current uncertainties in Nevzorov Probe efficiencies. The efficiencies are dependent on cloud particle size and phase. In this study a reasonable response of the critical efficiency $\varepsilon_{\mathrm{LWC}}$,droplets (LWC sensor efficiency with respect to water) was fixed from experimental data in Arctic clouds, where droplet sizes far beyond $25 \mu \mathrm{m}$ have been observed quite frequently. The efficiency $\varepsilon_{\mathrm{LWC}}$,droplets was estimated from the calculated size-dependent ratio of $\varepsilon_{\text {LWC,droplets }}$ over $\varepsilon_{\mathrm{TWC} \text {,droplets, }}$, assuming an extrapolation for

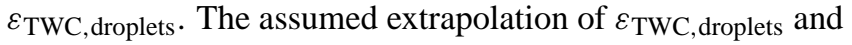
the assessment of $\varepsilon_{\mathrm{LWC} \text {,droplets }}$ as a function of cloud droplet diameters should lead to an improved adequacy of calculated condensed water contents (IWC, LWC). The proposed improvement in $\varepsilon_{\mathrm{LWC}}$,droplets is applied to calculate ice fractions sampled from the Nevzorov probe as a function of the asymmetry parameter deduced from the scattering phase function of the Polar Nephelometer.

Acknowledgements. This work was funded by the "Centre National d'Etudes Spatiales" (CNES), the "Institut Polaire Français Paul Emile Victor" (IPEV) and by a grant from the CNRS/INSU. We thank the members of Optimare and AWI (Alfred Wegener Institut) managing and organising the experiment and aircraft operations. We acknowledge C. Gourbeyre (LaMP) and J.-F. Fournol (LaMP) for their technical assistance and active accomplishment of the ASTAR measurement campaign.

Edited by: M. Wendisch

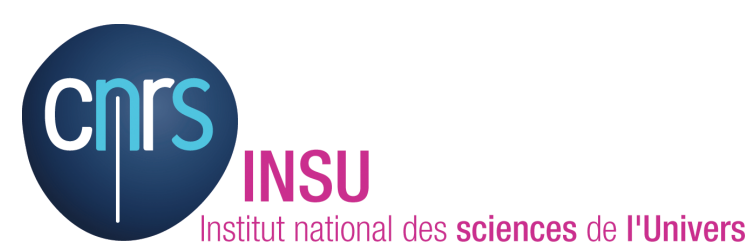

The publication of this article is financed by CNRS-INSU.

\section{References}

Baumgardner, D., Strapp, W., and Dye, J. E.: Evaluation of the forward scattering spectrometer probe, Part II: Corrections for coincidence and dead-time losses. J. Atmos. Ocean. Tech., 2, 626632, 1985.

Biter, C. J., Dye, J. E. Huffman, D., and King, W. D.: The drop response of the CSIRO liquid water content, J. Atmos. Ocean. Tech., 4, 359-367, 1987.

Emery, E., Miller, D., Plaskon, S., Strapp, J. W., and Lilie, L. E.: Ice Particle Impact on Cloud Water Content Instrumentation, 42nd AIAA Aerospace Sciences Meeting and Exhibit, AIAA-20040731, 2004.

Gardiner, B. A. and Hallett, J.: Degradation of in-cloud forward scattering spectrometer probe measurements in the presence of ice particles, J. Atmos. Ocean. Tech., 2, 171-180, 1985.

Garrett, T. J., Hobbs, P. V., and Gerber, H.: Shortwave, singlescattering properties of arctic ice clouds, J. Geophys. Res., 106, D14, 15.155-15.172, 2001.

Gayet, J. F., Brown, P. R. A., and Albers, F.: A comparison of incloud measurements obtained with six PMS 2-D-C probes, J. Atmos. Ocean. Tech., 10, 180-194, 1993. 
Gayet, J. F., Crepel, O., Fournol, J. F., and Oshchepkov, S.: A new airborne polar Nephelometer for the measurements of optical and microphysical cloud properties, Part I: Theoretical design, Ann. Geophys., 15(4), 451-459, 1997.

Gayet, J.-F., Stachlewska, I. S., Jourdan, O., Shcherbakov, V. N., Schwarzenboeck, A., and Neuber, R.: Microphysical and optical properties of precipitating drizzle and ice particles obtained from alternated lidar and in situ measurements, Ann. Geophys., 25(7), 1487-1497, 2007.

Gerber, H., Arends, B. G., and Ackerman, A. S.: New microphysics sensor for aircraft use, Atmos. Res., 31, 235-252, 1993

Hinds, W. C.: Aerosol technology: Properties, behaviour and measurement of airborne particles, John Wiley and Sons, ISBN 0471-19410-7, 464 pp., New York, USA, 1999.

King, W. D., Parkin D. A., and Handsworth R. J.: A hot-wire water device having fully calculable response characteristics, J. Appl. Meteor., 17, 1809-1813, 1978.

Korolev, A. V., Nevzorov, A. N., Strapp, J. W., and Isaac, G. A.: The Nevzorov Airborne Hot-Wire LWC-TWC Probe : Principle of Operation and Performance Characteristics, J. Atmos. Ocean. Tech., 15, 1495-1510, 1998.

Korolev, A. V., Strapp, J. W., Isaac, G. A., and Nevzorov, A. N.: In situ measurements of effective diameter and effective droplet number concentration, J. Geophys. Res., 27, 3993-4003, 1999.

Korolev, A. V. and Strapp, J. W.: Accuracy of Measurements of Cloud Ice Water Content by the Nevzorov Probe. 40th Aerospace Sciences Meeting and Exhibition, 14-17 January 2002, Reno, Nevada, AIAA, 2002.

Korolev, A. V., Isaac, G. A., Cober, S. G., Strapp, J. W., and Hallett, J.: Part A: Microphysical Characterization of Mixed Phase Clouds, Q. J. R. Meteorol. Soc., 129, 39-66, 2003.

Korolev, A. V., Strapp, J. W., Isaac, G. A., and Emery, E.: Improved airborne hot-wire measurements of ice water content in clouds, International Conference on Clouds and Precipitation, Cancun, Mexico, 2008.

Knollenberg, R. G.: Techniques for probing cloud microstructure. Clouds, their formation, optical properties and effects, edited by: Hobbs, P. V., Deepak, A., Academic Press, New York, 15-85, 1981.

Lawson, R. P., Korolev, A. V., Cober, S. G., Huang, T., Strapp, J. W., and Isaac, G. A.: Improved measurements of the drop size distribution of a freezing drizzle event, Atmos. Res., 48, 181$191,1998$.
Lawson, R. P., Baker B. A., Schmitt, C. G., and Jensen, T. L.: An overview of microphysical properties of Arctic clouds observed in May and July 1998 during FIRE ACE, J. Geophys. Res., 106, D14, 14989-15014, 2001.

Martin, G. M., Johnson D. W., and Spice A.: The measurement and parameterization of effective radius of droplets in stratocumulus clouds, J. Atmos. Sci., 51, 1823-1842, 1994.

Nevzorov, A. N.: "Aircraft cloud water content meter", (in Russian language), Transactions of Central Aerological Observatory (Trudi TsAO), 147, 19-26, 1983.

Nicholls, S., Leighton, J., and Barker, R. A. L.: A new fast-response instrument for measuring total water content from aircraft, J. Atmos. Oceanic Tech., 7, 706-718, 1990.

Ogren, J. A., Heintzenberg, J., and Charlson, R. J.: In situ sampling of clouds with a droplet to aerosol converter, Geophys. Res. Lett., 12(3), 121-124, 1985.

Ruskin, R. E.: Liquid water content devices, Atmos. Techn., 8, 3842, 1976.

Stachlewska, I. S., Gayet, J.-F., Duroure, C., Schwarzenboeck, A., Jourdan, O., Shcherbakov, V., and Neuber, R.: Observations of mixed phase clouds using airborne lidar and in situ instrumentation, Revived and revised Papers Presented at the 23rd International Laser Radar Conference, Chikao Nagasava and Nobuo Sugimoto, 325-328, 2006.

Strapp, J. W., Oldenburg, J., Ide, R., Lilie, L., Bacic, S., Vukovic, Z., Oleskiw, M., Miller, D., Emery, E., and Leone, G.: Wind Tunnel Measurements of the Response of Hot-Wire Liquid Water Content Instruments to Large Droplets, J. Atmos. Ocean. Techn., 20, 791-806, 2003.

Strapp, J. W., Lilie, L. E., Emery, E. E., and Miller, D. R.: Preliminary Comparison of Ice Water Content as Measured by Hot Wire Instruments of Varying Configuration, 43rd Aerospace Sciences Meeting and Exhibit, Reno, NV, AIAA-2005-0860, 11-13 January 2005.

Ström, J., Busen, R., Quante, M., Guillemet, B., Brown, P., and Heintzenberg, J.: Pre-EUCREX Intercomparison of Airborne Humidity Measuring Instruments, J. Atmos. Ocean. Techn., 11, 1392-1399, 1994

Voloshchuk, V. M.: The Introduction to the Hydrodynamics of Coarse-Dispersed Aerosols, Gidrometeoizdat, 208 pp., 1971.

Wendisch, M., Garrett, T. J., and Strapp, J. W.: Wind Tunnel Tests of the Airborne PVM-100A Response to Large Droplets, J. Atmos. Oceanic Techn., 19, 1577-1584, 2002. 